\title{
Did introduction of pneumococcal vaccines in the Netherlands decrease the need for respiratory antibiotics in children? Analysis of 2002 to 2013 data
}

G Gefenaite (g.gefenaite@alumnus.rug.nl) ${ }^{1,2}$, M J Bijlsma ${ }^{1}$, H J Bos ${ }^{1}$, E Hak Ha, $^{1,2}$

1. Department of Pharmacy, Unit of PharmacoEpidemiology \& PharmacoEconomics (PE2), University of Groningen, Groningen, the Netherlands

2. Department of Epidemiology, University Medical Centre Groningen, University of Groningen, the Netherlands

To estimate the effect of the introduction of the 7 - and 10-valentpneumococcal vaccines in 2006 and 2011, respectively in the Netherlands, we assessed respiratory antibiotic use in one to nine year-old children between 2002 and 2013. Seasonal autoregressive integrated moving-average models were applied to estimate the percentage reduction in respiratory antibiotic use. When compared with the pre-vaccination period, the proportion of respiratory antibiotic prescriptions fell by $4.94 \%$ (95\% Cl: 4.63 to 5.26 ) and $9.02 \%$ (95\% $\mathrm{Cl}: 2.83$ to 14.82$)$ after the introduction of the 7 -valent vaccine in children aged three and four years, respectively. After the introduction of the 10-valent vaccine, we observed a reduction of $13.04 \%$ (95\% Cl: 2.76 to 22.23), $20.31 \%$ (95\% Cl: 13.50 to 26.58 ), $16.92 \%$ (95\% Cl: 3.07 to 28.80 ), $22.34 \%$ (95\% Cl: 3.73 to 37.35 ), $23.75 \%$ (95\% Cl: 2.37 to 40.44 ) in two, three, four, six and seven year-old children, respectively. Thus, our results indicate a reduction in respiratory antibiotic prescriptions in young children after introduction of the pneumococcal vaccines. As only children in our study population aged one and two years born after March 2011 had received the 10-valent vaccine, the effects of the 10 -valent vaccine in children aged three to nine years likely reflect the effects of the 7 -valent vaccine and herd immunity.

\section{Introduction}

In 2001 in the Netherlands, $45 \%$ and $20 \%$ of all antibiotics in children were prescribed for respiratory tract and ear infections, respectively, with acute otitis media being the leading cause [1]. One of the common pathogens responsible for these infections, especially in young children, is Streptococcus pneumoniae. In the United States (US), it has been found in $44 \%$ of children hospitalised in 1999 to 2000 with community-acquired lower respiratory tract infections [2]. Due to substantial use of antibiotics for infections caused by S. pneumoniae [1], preventing these infections should remain an important public health goal.
In June 2006, 7-valent pneumococcal vaccination was introduced in the Netherlands as part of the national Dutch immunisation programme and was provided to all infants free of charge [3]. Prescription rates of oral antibiotics for children seemed to decrease after introduction of the vaccine [4], but no decline in ear, nose and throat problems has been observed [5]. The latter finding might be explained by replacement of pneumococcal serotypes. Despite an overall decrease in invasive pneumococcal disease (IPD) after the implementation of the 7 -valent vaccination campaign in the Netherlands, a decrease of vaccine-serotype IPD was followed by an increase in IPD caused by non-vaccine serotypes $[6,7]$. There has been no information, however, on any changes in use of antibiotics that are usually used for acute otitis media and pneumonia in young children (one to nine year-olds) in the Netherlands after the 7-valent pneumococcal vaccine was introduced. Moreover, in 2011, the 7 -valent pneumococcal vaccine was replaced by a 10-valent vaccine [8], whose effects have not yet been assessed in observational studies. Vaccinations were provided at two, three, four months and a booster dose at 11 months of age, with vaccination uptake rates of $94-95 \%$ [3].

To assess the patterns of respiratory antibiotic prescriptions in young children before and after the introduction of the pneumococcal vaccines in the Netherlands, we analysed the use of amoxicillin, azithromycin and sulfamethoxazole and trimethoprim from 2002 to 2013. In the Netherlands, antibiotics are available by prescription only. On the basis of Dutch general practitioner guidelines, these antibiotics are commonly prescribed for acute otitis media and pneumonia in children up to nine years of age in general practice $[9,10]$. We performed descriptive and time-series analyses to assess whether the introduction of the pneumococcal vaccines nationally reduced the proportion of respiratory antibiotic prescriptions in children one to nine years of age. 


\section{Methods}

The study population consisted of one to nine year-old children identified from the IADB.nl database, which contains pharmacy-dispensing data from community pharmacies in the Netherlands. A detailed description of this database is available elsewhere [11]).

The main outcome of our study was the proportion of monthly respiratory antibiotic prescriptions in a particular age group (the number of monthly prescriptions in the age group per month divided by the number of children in that age group in that month). The aggregated measure of respiratory antibiotic prescriptions per year (the number of monthly prescriptions in the age group per year divided by the number of children in that age group in that year) was calculated as well. The outcome measure was based on prescriptions for amoxicillin (Anatomical Therapeutical Chemical (ATC) code J01CA04), azithromycin (J01FA10) and/or sulfamethoxazole and trimethoprim (ATC code J01EE01), as described above. The name of the antibiotic dispensed, ATC code [12], date of prescription and birthdate of the children included in the study were extracted from the IADB.nl database.

The first intervention studied was the introduction of the 7 -valent pneumococcal vaccine in the Netherlands in June 2006 for all infants born after 1 April 2006 [3]. We also assessed the effects of the introduction of a 10 -valent pneumococcal vaccine for infants born after 1 March 2011 [8].

The study period was chosen based on some preliminary analyses: we excluded data before 2002 as we observed a decrease in respiratory antibiotic use between 1995 and 2002, which might have been due to policies and interventions targeted at decreasing antibiotic use, and it was not our aim to assess these interventions in this study. Given that, the pre-vaccination period was defined as 1 January 2002 to 31 March 2007 , i.e. the time before the 7 -valent introduction of the pneumococcal vaccine was assumed to start having an effect. We considered that an effect of the introduction of the 7-valent pneumococcal vaccine could first be seen from 1 April 2007, as we anticipated that all four doses of the vaccine, including the booster dose, would have been administered and had an effect within a year after birth. The end of the period to assess the effect of the 7-valent vaccine was 30 April 2011, i.e. before the 10 -valent vaccine replaced the 7 -valent vaccine.

To study any additional effect of the introduction of the 10 -valent pneumococcal vaccine, the end of the study period was set to 31 December 2013. We considered that an effect of the introduction of the 10-valent vaccine could first be seen from 1 March 2012, assuming that the full vaccination schedule would have been administered within a year after birth. The end of the study was 31 December 2013.
We assessed the effect of the 10-valent vaccine in two ways. We first ran the model including the introduction of both vaccines. Secondly, we assessed the effectiveness of the introduction of the 10 -valent vaccination campaign as compared to pre-vaccination period, when data points following introduction of the 7 -valent vaccine (1 June 2006 to 29 February 2012) were excluded.

Children born between 1 April 2006 and 28 February 2011 were assumed to have received the 7 -valent vaccine; children born before 1 April 2006 were assumed to have not been vaccinated, but potentially indirectly protected by vaccination of younger age groups. Children born after 1 March 2011 were assumed to have received the 10 -valent pneumococcal vaccine.

\section{Statistical analysis}

We first assessed the aggregated yearly respiratory antibiotic prescription proportions from 2002 to 2013 for each age group separately by plotting the data. We then assessed monthly antibiotic prescription proportions data using multiplicative decomposition [13] that shows the observed trend of the outcome as well as seasonal and random patterns, and the trend after removing the seasonal and random components.

To assess the effectiveness of the introduction of the pneumococcal vaccines, we used seasonal autoregressive integrated moving average (SARIMA $\left.(p, d, q)(P, D, Q)_{s}\right)$ time series models [14] with intervention analysis [15], where $p$ and $P$ is the number of auto-regressive components, $d$ and $D$ stands for differencing applied in the series, $q$ and $Q$ indicates the number of moving average components, and $\mathrm{s}$ is equal to the number of units of seasonal periods that are used in the model to remove additive seasonal effects. SARIMA allows us to estimate the effect of an intervention of interest by taking into account seasonal patterns. As pneumococcal illness tends to occur during the winter months, we assumed seasonal patterns occurring every 12 months, and therefore $\mathrm{s}$ was set to 12 . We estimated the level (the abrupt change) of respiratory antibiotic prescription proportions and the change in trend (the slope) after, as compared with before, the introduction of the pneumococcal vaccines. The intervention variables were coded as o before the intervention and 1 after the intervention. To assess the change in trends after the interventions were introduced, slope change variables denoting time were introduced. It was coded as o before the interventions, and afterwards counted the number of months after the introduction of the intervention of interest $[16,17]$.

The best SARIMA models were identified based on the Akaike Information Criterion (AIC) during the pre-vaccination period for each age group separately [18]. They were then applied to estimate the effects of the introduction of the 7 - and 10-valent vaccines throughout each part of the study period, as described above. When both interventions were included in the same model, the best model (the model with only the first intervention 
Proportion of yearly respiratory antibiotic prescriptions in children aged one to nine years, the Netherlands, 2002-13

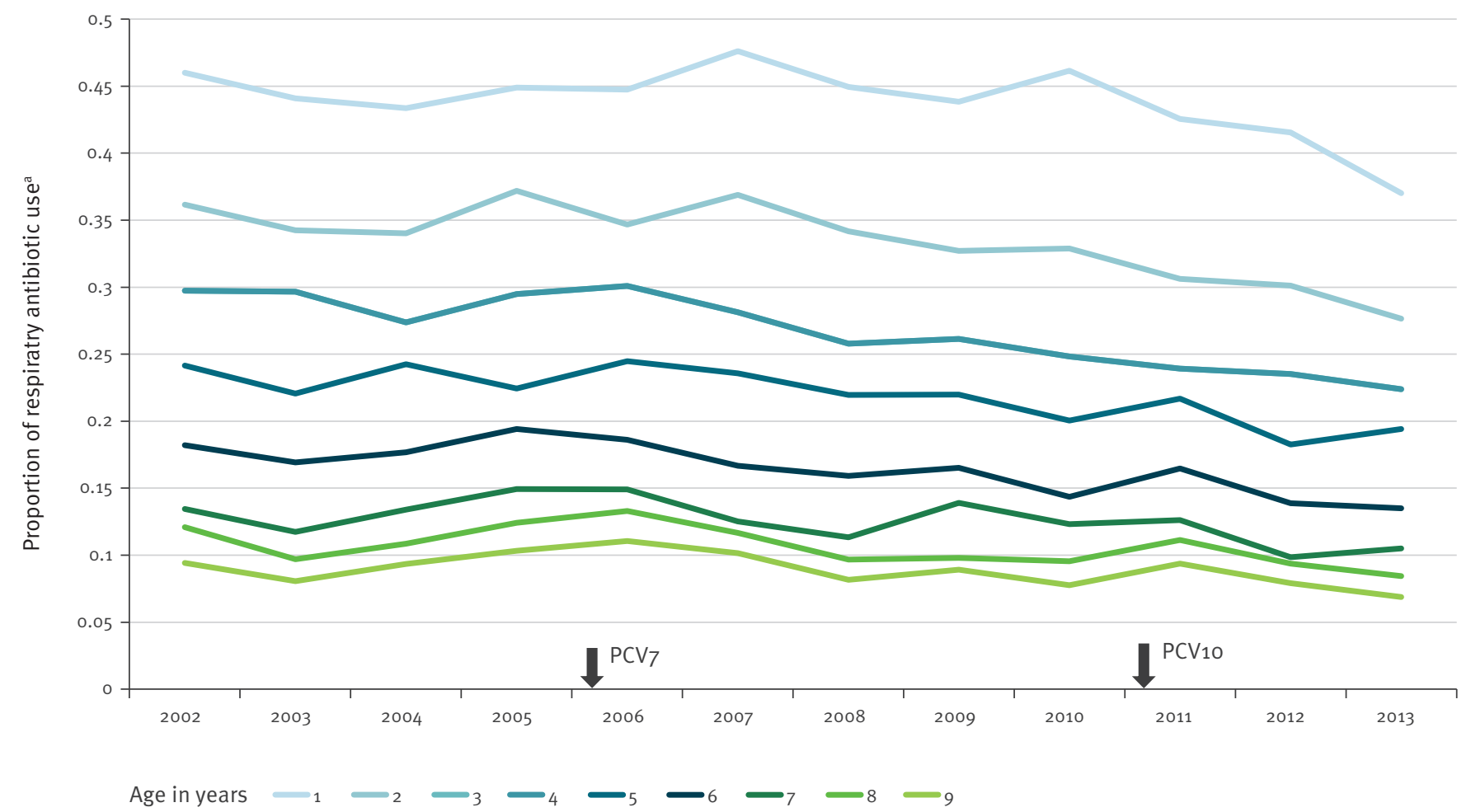

${ }^{a}$ Number of users per year/number of children in the particular age group in that year.

The children's ages shown are the age at which the antibiotic was prescribed.

(introduction of the 7 -valent vaccine) versus the model with both interventions) were selected based on a likelihood ratio test. The coefficients and their standard errors were estimated using maximum likelihood estimation. The percentage of change and its confidence intervals were calculated as (exp(coefficient) -1$) \times 100 \%$ and (exp(coefficient+/-1.96 xstandard error) -1$) \times 100 \%$. The adequacy of each model was verified by visually assessing the correlograms (there should be negligible residual autocorrelation) and the plots of the residuals (the residuals of the model should be randomly scattered). The analysis was performed with RStudio 0.97 .551 statistical software [19].

\section{Results}

Aggregated yearly estimates revealed that very young children had the most prescriptions of respiratory antibiotics: this decreased with age (Figure). We observed a slight decrease in respiratory antibiotic prescriptions after the introduction of the pneumococcal vaccines in 2006 and 2011 (Figure).We observed similar patterns when we inspected decomposed monthly trends of antibiotic prescriptions (data not shown).

To reveal the effects of the introduction of the pneumococcal vaccines on respiratory antibiotic prescriptions, we performed a time series analysis from 2002 to 2013. The best time series SARIMA models were identified based on AIC during the pre-vaccination period (see Table 1for the best model for each age group) and the likelihood ratio test when the additional effect of the introduction of the 10 -valent vaccine was assessed in the model, including both interventions at the same time. The final models did not show evidence of autocorrelation and we could not detect clear patterns in the residual autocorrelation for most of the age groups. Only the models for the eight and nine year-old children showed significant autocorrelation at lag 12, indicating a remaining seasonal effect. However, due to low levels of autocorrelation, it is unlikely that this would have had a strong effect on the overall results.

The level of respiratory antibiotic prescription proportions decreased after the introduction of the 7 -valent vaccine in most of the age groups (Table 1 ). The reduction was, however, only statistically significant in three and four year-old children, $-4.94 \%(95 \% \mathrm{Cl}$ : -5.26 to -4.63$)$ and $-9.02 \%$ (95\% Cl: -14.82 to -2.83$)$, respectively.

When we performed a likelihood ratio test, the model including both interventions was better than the model including the 7-valent vaccine intervention alone for a few age groups, namely in one, five and six year-olds. 
Effectiveness of introduction of 7-valent pneumococcal vaccine by age: change in level of respiratory antibiotic prescriptions and in trend of respiratory antibiotic prescription proportions, the Netherlands, 2002-13

\begin{tabular}{|c|c|c|c|}
\hline $\begin{array}{l}\text { Children's age } \\
\text { in years }\end{array}$ & $\begin{array}{c}\text { Change in level } \\
\text { Percentage }(95 \% \mathrm{Cl})\end{array}$ & $\begin{array}{l}\text { Change in trend } \\
\text { Percentage }(95 \% \mathrm{Cl})\end{array}$ & $\begin{array}{c}\text { Best SARIMA } \\
(p, d, q)(P, D, Q) 12 \text { model }\end{array}$ \\
\hline 1 & $1.20(-3.51$ to 6.13$)$ & $0.01(-0.13$ to 0.15$)$ & $(6,0,5)(8,1,9) 12$ \\
\hline 2 & $2.55(-1.85$ to 7.15$)$ & $-0.26(-0.42$ to -0.10$)$ & $(8,0,8)(5,0,5) 12$ \\
\hline 3 & $-4.94(-5.26$ to -4.63$)$ & $-0.16(\mathrm{NA})^{\mathrm{a}}$ & $(8,0,3)(7,0,7) 12$ \\
\hline 4 & $-9.02(-14.82$ to -2.83$)$ & $-0.11(-0.33$ to 0.11$)$ & $(8,0,4)(4,1,3) 12$ \\
\hline 5 & $-3.26(-7.39$ to 1.07$)$ & $-0.28(-0.47$ to -0.08$)$ & $(5,0,0)(9,0,9) 12$ \\
\hline 6 & $-10.10(-21.64$ to 3.14$)$ & $-0.11(-0.56$ to 0.34$)$ & $(2,0,3)(6,1,8) 12$ \\
\hline 7 & $-14.14(-35.28$ to 13.91$)$ & $0.15(-0.75$ to 1.06$)$ & $(0,0,1)(8,1,8) 12$ \\
\hline 8 & $-7.93(-24.17$ to 11.79$)$ & $-0.23(-0.85$ to 0.40$)$ & $(2,0,5)(3,1,0) 12$ \\
\hline 9 & $-12.72(-31.47$ to 11.17$)$ & $-0.20(-1.11$ to 0.72$)$ & $(0,0,0)(8,1,9) 12$ \\
\hline
\end{tabular}

$\mathrm{Cl}$ : confidence interval; NA: not applicable; SARIMA(p,d,q)(P,D,Q)s: seasonal autoregressive integrated moving average model with intervention analysis, where $p$ and $P$ is the number of auto-regressive components, $d$ and $D$ stands for differencing applied in the series, $q$ and $\mathrm{Q}$ indicates the number of moving average components and $\mathrm{s}$ is equal to the number of units of seasonal period that are used in the model.

a The standard error could not be approximated using the maximum likelihood algorithm.

However, estimates of the effect of the introduction of the 10-valent vaccine were inconsistent: the proportions of antibiotic prescriptions decreased and/or increased after the introduction of 7 - and/or 10 -valent vaccination and the results were not statistically significant (Table 2).

When we assessed the effectiveness of the introduction of the 10-valent vaccine as compared with the pre-vaccination period, we observed a reduction in respiratory antibiotic prescriptions of $-13.04 \%$ (95\% Cl: -22.23 to -2.76$),-20.31 \%$ (95\% Cl: -26.58 to -13.50$)$, $-16.92 \%$ (95\% Cl: -28.80 to -3.07$),-22.34 \%$ (95\% Cl: -37.35 to -3.73 ), $-23.75 \%$ ( $95 \% \mathrm{Cl}:-40.44$ to -2.37 ) in two, three, four, six and seven year-olds, respectively (Table 3).

The trends of antibiotic prescription proportions were similar before and after the interventions in most age groups (Tables 1-3).

\section{Discussion}

We found a decrease in antibiotic prescriptions for respiratory infections in three and four year-old children after the introduction of the 7-valent pneumococcal vaccine. Furthermore, we demonstrated that the introduction of the 10-valent pneumococcal vaccine continued to add benefit in terms of fewer respiratory antibiotic prescriptions. It is important to note, however, that the effect estimates of the latter intervention most likely include the effects of the 7 -valent vaccinations as well as herd immunity, as in our study, only children aged one and two years born after 1 March 2011 received the 10 -valent vaccine.

Our results are in line with the results from a recently conducted study on the effect of a 13-valent pneumococcal conjugate vaccine on admissions to hospital in the US: in children up to five years-old, introduction of the vaccine led to the reduction of all-cause, invasive pneumococcal and non-invasive pneumococcal or lobar pneumonia hospitalisation [20]. Such a decrease in outcomes, measured only a couple of years after

\section{TABLE 2}

Added effectiveness of introduction of 10 -valent pneumococcal vaccine for different ages ${ }^{\text {a }}$ : change in level and trend of antibiotic prescription proportions, the Netherlands, 2002-13

\begin{tabular}{|l|c|c|c|c|}
\hline \multirow{2}{*}{$\begin{array}{l}\text { Children's age } \\
\text { in years }\end{array}$} & $\begin{array}{c}\text { Change in level } \\
\text { Percentage }(95 \% \mathrm{Cl})\end{array}$ & $\begin{array}{c}\text { Change in trend } \\
\text { Percentage }(95 \% \mathrm{Cl})\end{array}$ & $\begin{array}{c}\text { 10-valent vaccine } \\
\text { Percentage }(95 \% \mathrm{Cl})\end{array}$ & $\begin{array}{c}\text { Change in trend } \\
\text { Percentage }(95 \% \mathrm{Cl})\end{array}$ \\
\cline { 2 - 5 } & $5.54(2.74$ to 8.41$)$ & $-0.13(-0.21$ to -0.05$)$ & $-6.27(-17.57$ to 6.56$)$ & $-0.63(-1.52$ to 0.27$)$ \\
\hline 5 & $2.72(-3.92$ to 9.82$)$ & $-0.29(-0.50$ to -0.07$)$ & $1.35(-16.03$ to 22.33$)$ & $0.32(-0.87$ to 1.53$)$ \\
\hline 6 & $-10.32(-21.03$ to 1.85$)$ & $-0.08(-0.41$ to 0.25$)$ & $-0.08(-0.41$ to 0.25$)$ & $-9.72(-28.15$ to 13.44$)$ \\
\hline
\end{tabular}

$\mathrm{Cl}$ : confidence interval.

a Included are only the ages for which an added effect of the introduction of the 10-valent vaccine was demonstrated, based on a likelihood ratio test. 
TABLE 3

Effectiveness of introduction of 10-valent pneumococcal vaccine for children aged one to nine years: change in level and trend of antibiotic prescription proportions as compared with the pre-vaccination period ${ }^{\text {a }}$, the Netherlands

\begin{tabular}{|l|c|c|}
\hline $\begin{array}{l}\text { Children's age } \\
\text { in years }\end{array}$ & $\begin{array}{c}\text { Change in level } \\
\text { Percentage }(95 \% \mathrm{Cl})\end{array}$ & \multicolumn{1}{c|}{$\begin{array}{c}\text { Change in trend } \\
\text { Percentage }(95 \% \mathrm{Cl})\end{array}$} \\
\hline 1 & $0.22(-8.92$ to 10.28$)$ & $-1.43(-2.16$ to -0.69$)$ \\
\hline 2 & $-13.04(-22.23$ to -2.76$)$ & $-0.80(-1.69$ to 0.10$)$ \\
\hline 3 & $-20.31(-26.58$ to -13.50$)$ & $-0.04(-0.94$ to 0.87$)$ \\
\hline 4 & $-16.92(-28.80$ to -3.07$)$ & $-0.66(-1.70$ to 0.40$)$ \\
\hline 5 & $-11.94(-24.26$ to 2.38$)$ & $-0.47(-1.73$ to 0.81$)$ \\
\hline 6 & $-22.34(-37.35$ to -3.73$)$ & $-0.56(-2.14$ to 1.05$)$ \\
\hline 7 & $-23.75(-40.44$ to -2.37$)$ & $-0.51(-2.29$ to 1.30$)$ \\
\hline 8 & $-15.11(-41.20$ to 22.57$)$ & $-1.75(-3.81$ to 0.35$)$ \\
\hline 9 & $-29.29(-51.52$ to 3.14$)$ & $-0.63(-2.94$ to 1.74$)$ \\
\hline
\end{tabular}

$\mathrm{Cl}$ : confidence interval.

a Pre-vaccination period: 1 January 2002 to 31 May 2006.

introduction of the new vaccine covering more serotypes and with vaccination coverage in children up to five years-old of $54 \%$ in the US study indicates not only direct, but also indirect protection. We also found that, although it was not statistically significant, there was an indication of a decrease in prescriptions of respiratory antibiotics in unvaccinated children aged eight and nine years born before the introduction of pneumococcal vaccination.

Our point estimates of the effect of the introduction of the pneumococcal vaccines showed a decrease, but it was not always statistically significant. Even though overall antibiotic prescription trends had a decreasing pattern, after the introduction of the vaccines, there were some fluctuations. The effects of the pneumococcal vaccines might therefore have been not significant due to quite low overall use of antibiotics in the Netherlands $[1,21]$, thus making the data more sensitive to fluctuations. Moreover, it has been documented that after the introduction of the 7 -valent pneumococcal vaccine in the Netherlands, invasive pneumococcal disease rates caused by non-vaccine serotypes increased $[6,7]$. This might also partly explain the observed fluctuations, even after the introduction of the vaccines. However, in our study, we were unable to explore the effect of serotype replacement, since serotype-specific clinical outcome data were not part of the dataset.

We may not have been able to show the benefits of the 10 -valent pneumococcal vaccination in addition to the 7-valent campaign due to several reasons. First, the 10 -valent vaccine covers additional three serotypes, meaning that the relative benefit of this campaign might be too small to detect when compared with the 7-valent vaccine. Additionally, as mentioned above, we observed some fluctuation (small increases and decreases) in the data following the introduction of the vaccines. These factors might explain why there was no statistically significant added benefit of the 10 -valent vaccine and that for several ages, the model including the 7 -valent vaccine alone appeared to be better than the model including both campaigns. These explanations seem plausible because when we assessed the effect of the 10 -valent vaccine as compared with the pre-vaccination period, the observed reduction in respiratory antibiotic prescription proportions was large, reaching for some ages above $20 \%$.

Because the pneumococcal vaccines targeted welldefined population groups at the national level at well-defined time points and vaccination uptake rates were high $(94-95 \%)[3,8]$, we were able to study the effects of the interventions at the population rather than individual level. This is advantageous as large population-based databases, such as IADB.nl, which do not include individual vaccination information, can still be used to assess the impact of population-based interventions. By using SARIMA time-series models, we were able to estimate direct (among children age done to seven years) and indirect (among eight to nine year-olds) effects of the introduction of the pneumococcal vaccines. We were able to take seasonal effects into account as well as assess the introduction of both the 7 -valent and 10 -valent pneumococcal vaccinations by using different approaches.

Although we did not have information about the reason for the antibiotic prescriptions, the antibiotics that we looked at are specifically recommended to treat acute otitis media and pneumonia in young children in the Netherlands $[9,10]$. As $S$. pneumoniae is one of the leading causes of mucosal infections [22], our results are likely to indicate an effect of the introduction of the pneumococcal vaccines on health problems caused by S. pneumoniae. 
In conclusion, our study provides evidence that introduction of the 7- and 10-valent pneumococcal vaccines were effective in reducing respiratory antibiotic prescriptions in young children, with a reduction of about $5-24 \%$ in antibiotic prescriptions for mucosal infections likely due to the introduction of the pneumococcal vaccines. Nevertheless, it is important to keep in mind that due to its recent introduction, the effect of the introduction of the 10 -valent vaccine is likely in part due to the continuing effects of the 7 -valent vaccine and herd immunity. Future studies are needed to further assess the effects of the pneumococcal vaccines on different health outcomes as well on populations other than children.

\section{Conflict of interest}

None declared.

\section{Authors' contributions}

Designed the study: GG. Prepared and analysed data: GG, MJB, JB. Interpreted the results: GG, MJB. Wrote the first draft: GG. Revised the article: GG, MJB, JB, EH. All authors read and approved the final manuscript.

\section{References}

1. Otters HB, van der Wouden JC, Schellevis FG, van SuijlekomSmit LW, Koes BW. Trends in prescribing antibiotics for children in Dutch general practice. J Antimicrob Chemother. 2004;53(2):361-6. http://dx.doi.org/10.1093/jac/dkho62

2. Michelow IC, Olsen K, Lozano J, Rollins NK, Duffy LB, Ziegler T, et al. Epidemiology and clinical characteristics of communityacquired pneumonia in hospitalized children. Pediatrics. 2004;113(4):701-7. http://dx.doi.org/10.1542/peds.113.4.701

3. van Lier EA, Oomen PJ, Giesbers H, Drijfhout IH, de Hoogh $\mathrm{PA}$, de Melker HE. Vaccinatiegraad Rijksvaccinatieprogramma Nederland.Verslagjaar 2011. [Immunization coverage National Immunization Programme in the Netherlands: Year of report 2011]. Bilthoven: National Institute for Public Health and the Environment (RIVM); 2011. Report 210021014/2011. Dutch. Available from: http://www.rivm.nl/bibliotheek/ rapporten/210021014.pdf

4. de Bont EG, van Loo IH, Dukers-Muijrers NH, Hoebe CJ, Bruggeman CA, Dinant GJ, et al. Oral and topical antibiotic prescriptions for children in general practice. Arch Dis Child. 2013;98(3):228-31. http://dx.doi.org/10.1136/ archdischild-2012-303134

5. Uijen JH, Bindels PJ, Schellevis FG, van der Wouden JC. ENT problems in Dutch children: trends in incidence rates, antibiotic prescribing and referrals 2002-2008. Scand J Prim Health Care. 2011; 29(2):75-9. http://dx.doi.org/10.3109/02813 432.2011.569140

6. Rodenburg GD, de Greeff SC, Jansen AG, de Melker HE, Schouls $L M$, Hak E, et al. Effects of pneumococcal conjugate vaccine 2 years after its introduction, the Netherlands. Emerg Infect Dis. 2010;16(5):816-23. http://dx.doi.org/10.3201/eid1605.091223

7. Elberse KE, van der Heide HG, Witteveen S, van de Pol I, Schot CS, van der Ende A, et al. Changes in the composition of the pneumococcal population and in IPD incidence in The Netherlands after the implementation of the 7 -valent pneumococcal conjugate vaccine.Vaccine. 2012;30(52):764451. http://dx.doi.org/10.1016/j.vaccine.2012.04.021

8. van't Klooster T, de Melker H. The National Immunisation Programme in the Netherlands: Developments in 2011. Bilthoven: National Institute for Public Health and the Environment (RIVM); 2012. Report 210021015/2011 Available from: http://www.rivm.nl/dsresource?objectid=rivmp:121041\& ype $=$ org\&disposition $=$ inline\&ns_nc $=1$

9. Dutch College of General Practitioners (NHG). NHG-Standaard, Otitis media acuta bij kinderenMog (Actualisering 2013: herzient.o.v. de versie van 2006). [The Dutch College of General Practitioners Guidelines, Otitis media acuta in children Mog (Updated in 2013: based on the version of 2006)]. Utrecht:
NHG; 2006 (in revision). [Accessed 19 Mar 2013]. Dutch. Available from: http://nhg.artsennet.nl/kenniscentrum/k richtlijnen/k_nhgstandaarden/SamenvattingskaartjeNHGStandaard/Mo9_svk.htm

10. Dutch College of General Practitioners (NHG).NHGStandaarden, Acuut hoesten M78 (Actualisering 2013: herzien t.o.v. de versie van 2011). [The Dutch College of General Practitioners Guidelines, Acute cough M78 (Updated in 2013: based on the version of 2011)]. Utrecht: NHG; 2013. [Accessed 19 Mar 2013]. Dutch. Available from: http://nhg. artsennet.nl/kenniscentrum/k_richtlijnen/k_nhgstandaarden/ Samenvattingskaartje-NHGStandaard/M78_svk.htm

11. Visser ST, Schuiling-Veninga CC, Bos JH, de Jong-van den Berg LT, Postma MJ. The population-based prescription database IADB. nl: its development, usefulness in outcomes research and challenges. Expert Rev Pharmacoecon Outcomes Res. 2013;13(3):285-92. http://dx.doi.org/10.1586/erp.13.20

12. World Health Organization (WHO) Collaborating Centre for Drug Statistics Methodology. ATC/DDD Index 2005. Oslo: WHO Collaborating Centre for Drug Statistics Methodology. [Accessed 19 Mar 2013].

13. Cowpertwait PS, Metcalfe AV. Introductory time series with R. Berlin: Springer; 2009.

14. Box GE, Jenkins GM, Reinsel GC. Time series analysis, forecasting and control. 3rd ed. Englewood Cliff, NJ: Prentice Hall; 1994 .

15. Box GE, Tiao GC. Intervention analysis with applications to economic and environmental problems. J Am StatAssoc. 1975;70(349):70-9. http://dx.doi.org/10.1080/01621459.1975. 10480264

16. HuitemaBE, Mckean JW. Design specification issues in time-series intervention models. Educ Psychol Meas. 2000; 6o(1):38-58. http://dx.doi.org/10.1177/00131640021970358

17. Wagner AK, Soumerai SB, Zhang F, Ross-Degnan D. Segmented regression analysis of interrupted time series studies in medication use research. J Clin Pharm Ther. 2002;27(4):299309. http://dx.doi.org/10.1046/j.1365-2710.2002.00430.x

18. Time-series analysis. In: Tabachnick B, Fidell L. Using multivariate statistics. 5 th ed. Chapter 18. Needham Heights, MA: Allyn \& Bacon; 2006.

19. Ihaka R, Gentleman R. R: a language for data analysis and graphics. J Comput Graph Stat. 1996;5(3):299-314.

20. Simonsen L, Taylor RJ, Schuck-Paim C, Lustig R, Haber M, Klugman KP. Effect of 13 -valent pneumococcal conjugate vaccine on admissions to hospital 2 years after its introduction in the USA: a time series analysis. Lancet Respir Med. 2014;2(5):387-94 http://dx.doi.org/10.1016/ S2213-2600(14)70032-3

21. Goossens H, Ferech M, Vander Stichele R, Elseviers M; ESAC Project Group. Outpatient antibiotic use in Europe and association with resistance: a cross-national database study. Lancet. 2005;365(9459):579-87. http://dx.doi.org/10.1016/ S0140-6736(05)17907-0

22. Weil Olivier C. Ten years of experience with the pneumococcal conjugate 7-valent vaccine in children. Med Mal Infect. 2013;43(8):309-21. http://dx.doi.org/10.1016/j. medmal.2013.04.006 